\title{
Discussion: Active earth pressures from a log-spiral slip surface with arching effect
}

\author{
Y. XIE*, B. LESHCHINSKY*, R. GANESH† and J. P. SAHOO†
}

\author{
ICE Publishing: all rights reserved
}

\section{DISCUSSION BY R. GANESH AND J. P. SAHOO}

Xie \& Leshchinsky (2016) presented the variation of active earth pressure acting on retaining walls by taking into account the arching effect based on a log-spiral failure mechanism using the numerical approach. Using planar failure mechanism, Paik \& Salgado (2003) have developed a closed-form expression for determining the active earth pressure distribution and the resultant earth pressure. With reference to Figs 3(a)-3(d) in Xie \& Leshchinsky (2016), the solutions of Paik \& Salgado (2003) were found to be in very close agreement with the experimental results and better than that of Coulomb. The solutions of Xie \& Leshchinsky (2016) are expected to be better than that of Paik \& Salgado (2003) thanks to considering a non-linear failure surface which most likely represents the true shape of the failure surface for finding the maximum magnitude of the active earth pressure; however, the active earth pressure computed by Xie \& Leshchinsky (2016) has been found even lower than Coulomb's solution. In their analysis, the rotation of the principal axes that occur due to arching of backfill soil at any depth $z$ below the horizontal ground was considered by keeping the direction of the major principal stress normal to the ground surface. This consideration does not warrant the satisfaction of Mohr-Coulomb criterion along the failure surface at all depths except when the inclination of failure surface with the minor principal axis makes an angle of $45^{\circ}+\phi / 2$ (Peng \& Chen, 2013). The assumed direction of the principal axes by Xie \& Leshchinsky (2016, Fig. 2(a)) is only valid for the planar failure surface making an angle $45^{\circ}+\phi / 2$ with respect to the horizontal. This assumption seems to lead to an error in the analysis given that the results obtained by the authors may be found to be less than that of Coulomb. Furthermore, the parameter $N$ representing the ratio of the major to minor principal stresses appears to be not valid since the inclination of the tangent to the failure surface with the minor principal stress at any depth $z$ needs to make an angle of $45^{\circ}+\phi / 2$.

\section{AUTHORS' REPLY}

The results presented in Xie \& Leshchinsky (2016) are attained using a limit equilibrium (LE) framework with a maximisation procedure to derive potential active, arching pressures behind rigid retaining structures stemming from a log-spiral slip surface. LE inherently involves the analysis of multiple, potentially unstable bodies, restrained externally by a wall, where stresses (or forces) for a given slip surface are typically evaluated using the Mohr-Coulomb failure criteria along its extents without direct evaluation of principal

Published online at www.geotechniqueletters.com on 7 September 2016.

*School of Civil and Construction Engineering, Oregon State University, Corvallis, OR, USA

$\dagger$ Department of Civil Engineering, Indian Institute of Technology, Roorkee, India. stresses (e.g. the Coulomb approach). The work presented in Xie \& Leshchinsky (2016) uses an extremisation procedure that evaluates the active resultant stemming from a series of horizontal slices that discretise a potential log-spiral failure mechanism. Ultimately, a maximum active resultant for a series of log-spirals is determined in an iterative process (Fig. 1) - a similar technique has been used by other researchers for 'singular, assumed' failure mechanisms (e.g. Paik \& Salgado, 2003; Khosravi, 2012). Within each horizontal slice, normal, lateral and shear forces are determined along the internal (wall) and external (incremental length of slip surface) boundaries within an LE framework, ultimately yielding the expected arching pressures within each slice element. The use of iterative LE ultimately enables a generalised approach towards evaluating active, arching earth pressures stemming from a log-spiral mechanism for 'various wall geometries and slip surfaces' (Fig. 2). This generalisation is beneficial as a log-spiral can capture curved and relatively planar slip surface geometry. Conversely, previous methods that evaluate planar slip surfaces do not demonstrate the versatility of transitioning into a curvilinear surface. A log-spiral tends to degenerate into a (practically) planar surface when little interface friction between the wall and the retained soil is present, but demonstrates curvilinearity when interface friction is significant - a feature that has not been captured in earlier studies.

The discussers highlighted that the inclination of a failure surface with the minor principal axis realised at an angle of $45^{\circ}+\phi / 2$ is not fulfilled by the log-spiral failure surface; however, the same imposed, approximate inclination has been implemented by others to explore the relevant arching behaviour within an investigatory exercise. For example, Goel \& Patra (2008) considered a parabolic failure surface for the arching problem to derive lateral earth pressures, assuming that the major principal stresses at the failure surface were normal to the ground surface. The minor principal axis may not realise an angle of $45^{\circ}+\phi / 2$ with the failure surface for all depths, but their results established reasonable agreement when compared with experimental data and other analytical solutions. 'This demonstrates that such an approximation is reasonable in an average sense'. A similar assumption made by Xie \& Leshchinsky (2016) was intended as an exploratory means of evaluating arching pressures for a more versatile failure mechanism. It also demonstrated similar, reasonable agreement with other analytical solutions and experimental data. Improved consideration of principal stresses may be feasible, but were out of the scope of the exploratory numerical results presented by the authors.

Ultimately, a comparison with the experimental results is a desired means to validate a proposed analytical or numerical solution, but one must understand that these results have difficulty capturing 'all' important considerations in soil mechanics and experimentation that may affect realised results. For example, none of the presented solutions for arching in the literature can perfectly account for soil anisotropy, bedding planes from compaction or pluviation, 


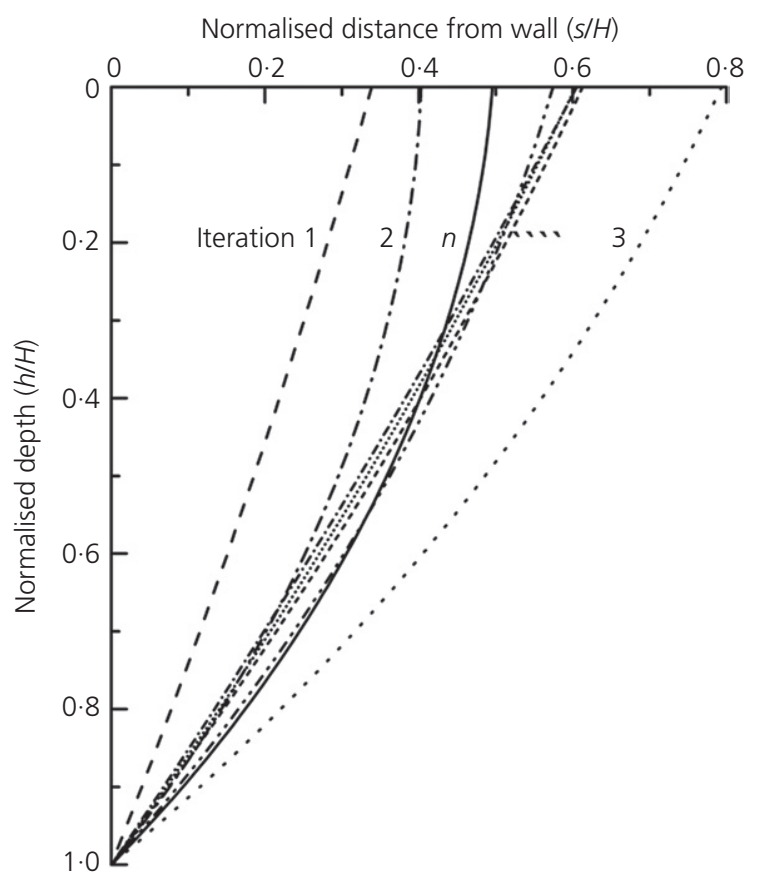

Fig. 1. Extremisation process for finding the critical log-spiral failure surface moisture content and suction stress, cementation, grain size distribution, grain shape and experimental measurement errors. However, all of these factors play a role within the results determined from a given experimental design. To say it succinctly, just because one method 'agrees' better with a limited set of experimental results does not mean that new, proposed solutions are unnecessary. This is particularly true if a procedure considers fundamentally new applications to a more generalised geometry (wall batter, log-spiral slip surface). The discussers mention that the presented approach realises smaller active resultant forces than those derived from Coulomb when compared with the experimental results from Tsagareli (1965), while the results still demonstrate reasonable agreement. While true, little consideration is given to the aforementioned uncertainties in experimental results. Accounting and 'correcting' for soil properties that are neglected from these analyses (inhomogeneity, real anisotropic properties) could easily demonstrate that any approach, including the proposed approach, is 'the most accurate'. However, using one's judgment, one might ask: 'Is it?' While the proposed LE extremisation process may provide results slightly different than those from Tsagareli (1965), they still capture the same reasonable trends for active resultant and the resultant location captured by Handy (1985), Paik \& Salgado (2003) and Tsagareli (1965). Going further, if the presented experimental results are 'perfect', then the proposed approach demonstrates the best agreement of all the

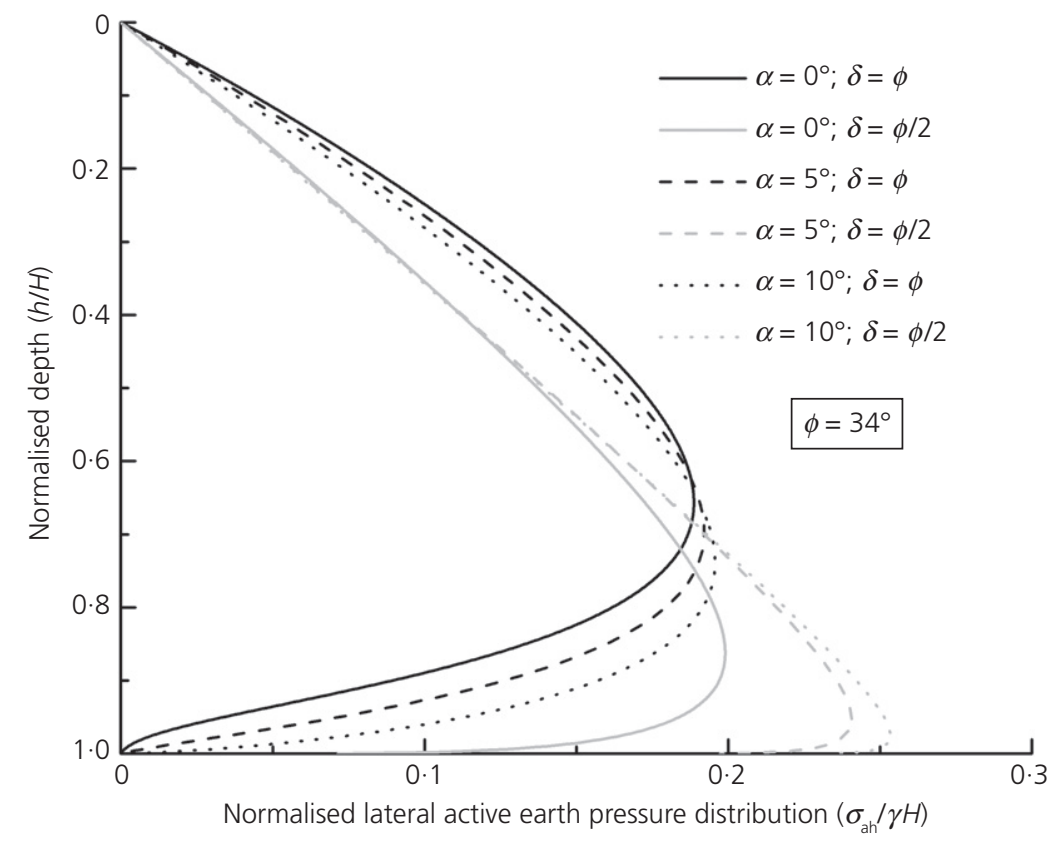

(a)

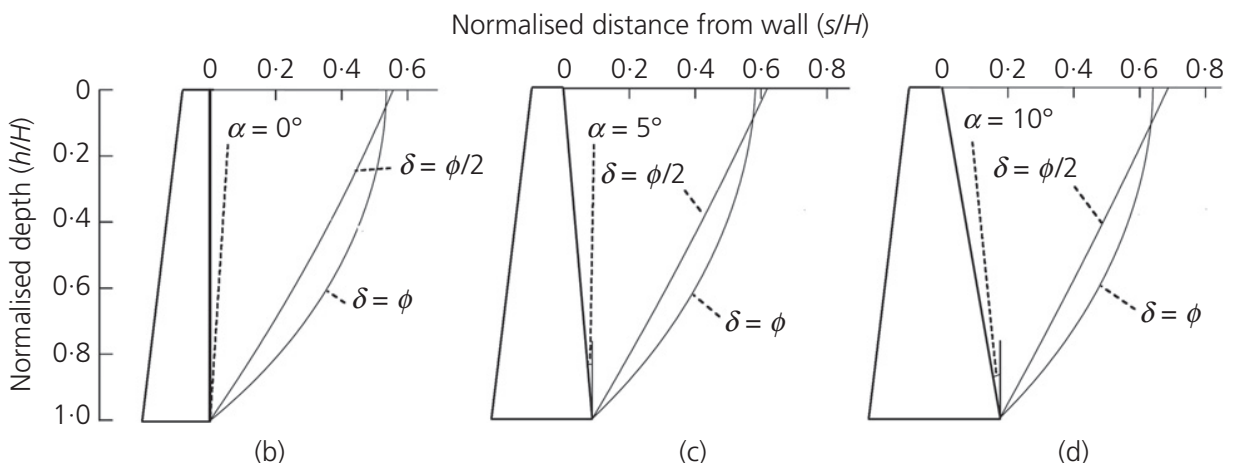

(b)

(c)

(d)

Fig. 2. Lateral earth pressure for battered walls for different $\delta$ 
proposed methods for determining the resultant location. However, the authors understand that absolute differences (or agreement) for comparisons to experimental approaches are simply a means to an end: a means to validate methods to quantify the general behaviour of an inherently complex material - soil. In summary, the discussed paper provides one potential approach towards evaluating arching in geometry that has not been accounted for previously. This enables more flexibility for others to compare and understand the results of their experiments or field tests, not to proclaim that one approach is better than another.

\section{REFERENCES}

Goel, S. \& Patra, N. R. (2008). Effect of arching on active earth pressure for rigid retaining walls considering translation mode. Int. J. Geomech. 8, No. 2, 123-133.

Handy, R. L. (1985). The arch in soil arching. J. Geotech. Engng 111, No. 3, 302-318.
Khosravi, M. H. (2012). Arching effect in geomaterials with applications to retaining walls and undercut slopes. $\mathrm{PhD}$ dissertation, Department of International Development Engineering, Graduate School of Science and Engineering, Tokyo Institute of Technology, Tokyo, Japan.

Paik, K. H. \& Salgado, R. (2003). Estimation of active earth pressure against rigid retaining walls considering arching effects. Géotechnique 53, No. 7, 643-653, http://dx.doi.org/10.1680/geot. 2003.53.7.643.

Peng, M. X. \& Chen, J. (2013). Slip-line solution to active earth pressure on retaining walls. Géotechnique 63, No. 12, 1008-1019, http://dx.doi.org/10.1680/geot.11.P.135.

Tsagareli, Z. V. (1965). Experimental investigation of the pressure of a loose medium on retaining walls with a vertical back face and horizontal backfill surface. Soil Mech. Found. Engng 2, No. 4, 197-200.

Xie, Y. \& Leshchinsky, B. (2016). Active earth pressures from a log-spiral slip surface with arching effect. Géotech. Lett. 6, No. 2, 149-155, http://dx.doi.org/10.1680/jgele.16.00015. 